\title{
KONTRUKSI PEREMPUAN DALAM FILM HANTU SUNDEL BOLONG
}

\section{WOMEN CONSTRUCTION ON SUNDEL BOLONG GHOST FILM}

\author{
Dheka Dwi Agustiningsih dan Ani Rostiyati \\ Program Studi Bahasa dan Sastra, UPI \\ Jl. Setiabudi No. 229 Sukasari Kota Bandung \\ Balai Pelestarian Nilai Budaya Jawa Barat \\ J1. Cinambo No.136, Ujung Berung, Jl. Cisaranten Wetan, Bandung \\ E-mail: anirostiyati@yahoo.com \\ DOI: $10.36424 / j p s b . v 5 i 1.25$ \\ Naskah Diterima: 8 April 2019 Naskah Direvisi:26 Mei 2019 Naskah Disetujui: 04 Juni 2019
}

\begin{abstract}
Abstrak
Penelitian ini mengkaji film-film horor yang mengangkat mitos mengenai hantu Sundel Bolong sebagai tema cerita. Empat film yang menjadi objek penelitian ini yaitu: Sundel Bolong (1981), Malam Jumat Kliwon (1986), Legenda Sundel Bolong (2007), dan Sundel Bolong 2 (2008). Keempat film tersebut mengisahkan tentang perempuan yang menjadi sundel bolong. Tujuan penelitian ini adalah untuk mengafirmasi kekerasan seksual yang dialami perempuan. Penelitian ini menggunakan sudut pandang feminisme yang mencakup pembahasan mengenai hubungan seksual, femme fatale, dan teori film feminis. Kajian ini menggunakan metodologi interpretatif yakni suatu pendekatan tafsir yang menggunakan "teks" sebagai analogi atau model yang memandang, memahami, dan menafsirkan suatu kebudayaan atau gejala sosial budaya tertentu. Kesimpulan dari penelitian ini adalah perempuan dalam film sundel bolong merupakan objek dalam hubungan seksual dan kematiannya merupakan kebangkitannya dalam wujud hantu. Sundel Bolong yang kecewa terhadap laki-laki dan frustrasi muncul sebagai sosok femme fatale dan membalas dendam dengan menggunakan tipu muslihat feminin seperti kecantikan, pesona, dan daya tarik seksual. Penindasan seksualitas perempuan adalah subteks penting dari film horor bertema Sundel Bolong.

Kata Kunci: Kontruksi parempuan, film, hantu sundel bolong
\end{abstract}

\begin{abstract}
This study discusses horror films related to the myth about the ghost of Sundel Bolong as the main theme. The four films As the object of this research were Sundel Bolong (1981), Malam Jumat Kliwon(1986), Legenda Sundel Bolong (2007), and Sundel Bolong 2 (2008). The four films tell the story of women as the who became a Sundel Bolong. The purpose of this study is to affirm the sexual violence experienced by women. This research was carried out using a feminist point of view, including discussions on sexual relations, femme fatale, and feminist film theory. This study uses interpreative methodology, which is an interpretive approach that uses "text" as an analogy or model that views, understands, and interprets a particular culture or phenomenon of social culture. The conclusion of this study is that women in Sundel Bolong film are objects in sexual relations and their death in the form of ghosts. Sundel
\end{abstract}


Bolong, who is disappointed with men and frustrated with her life (from the public's view) appears as a femme fatale and takes revenge by using feminism tricks such as beauty, charm, and sexual attraction. The suppression of female sexuality is an important subtext of a horror film themed Sundel Bolong.

Keywords: women construction, film, ghost of sundel bolong

\section{PENDAHULUAN}

Dinamika perfilman di tanah air memang tidak akan lepas dari perkembangan genre-genre film itu sendiri. Semenjak prakemerdekaan perfilman kita tidak lepas dari film bergenre horor, bahkan pada tahun 1934, film bergenre mistik. Sampai tahun 1980-an film horor dikenal dengan sebutan film mistik. Film-film ini mengangkat kepercayaan dan takhayul yang berkembang di masyarakat. Pertama diproduksi berjudul Ouw Peh Tjoa (Doea Siloeman Oeler Poeti en Item) yang diangkat dari cerita klasik Cina. Kisah ini kemudian bersambung ke film Anaknja Siloeman Oelar Poeti tahun 1936, dan pada tahun 1934 juga diproduksi film serupa berjudul Tie Pat Kai Kawin (Siloeman Babi Perang Siloeman Monjet).

Dinamika film kian berkembang tanpa menghilangkan mitos-mitos yang telah hidup dalam masyarakat. Jika pada masa prakemerdekaan cerita klasik Cina cukup banyak diangkat sebagai film horor, maka pada masa pascakemerdekaan misalnya pada tahun 1973 diproduksi sebuah film yang mengangkat cerita yang berkembang secara lisan di daerah Betawi yaitu Si Manis Jembatan Ancol. Lalu, pada tahun 1980an film horor populer bersimbiosis dengan kepopuleran aktris perempuan Suzzanna.

Film horror yang didominasi oleh Suzzanna sebagai pemeran utamanya, banyak mengangkat mitos-mitos nusantara seperi Nyi Blorong, Nyi Roro Kidul, Sundel Bolong, Kuntilanak, dan sebagainya. Pada tahun 1981 film berjudul Sundel Bolong berhasil meraih kesuksesaan dengan tercapainya penonton sampai dengan jumlah 301.280. Pada tahun 1986, Suzzanna kembali membintangi film horor sebagai hantu Sundel Bolong dalam film Malam Jumat Kliwon.

Dalam era "Suzzanna", ada dua karakter cerita yang diusung dalam film horor, yaitu: 1) mengenai perempuan-perempuan yang memiliki kekuatan seperti 
dalam film Nyi Blorong, Nyi Loro Kidul, dan sebagainya; 2) mengenai mitos-mitos hantu perempuan yang balas dendam karena ketika hidup mereka dikecewakan, dilukai, dan bahkan dibunuh, seperti dalam film Sundel Bolong, Malam Jumat Kliwon, Malam Satu Sura, Santet dan sebagainya. Karakter yang berbeda lagi muncul pada era "Joice Erna, Kiki Fatmala, dan Sally Marcelina". Pada era tersebut banyak diusung cerita mengenai perempuan yang menjadi korban perselingkuhan, diperkosa, dan kemudian mati dan menjadi hantu lalu diselesaikan dengan kehadiran seorang kiai misalnya Pembalasan Setan Karang Bolong, Nyi Lamped, Perjanjian Terlarang, dan sebagainya. Film horor pada era ini banyak dibumbui dengan adegan seks.

Sementara itu, karakteristik lain muncul pada era 2000an. Pada era ini karakter film horor cukup beragam, mulai dari yang mengangkat mitos hantu tradisional, seperti film Kuntilanak, Sundel Bolong, Pocong, dan Leak, ada pula cerita mengenai mitos yang bersifat lokal seperti Rumah Pondok Indah, Hantu Jeruk Purut, Terowongan Casablanca, Angkerbatu, dan sebagainya. Pada tahun 2006, film bergenre horor yang lolos sensor meningkat. Film horor akhirnya mampu menggantikan film percintaan remaja sebagai pendulang uang. Film Kuntilanak, menururt produsernya yaitu Raam Punjabi, berhasil mencapai angka penonton 1,3 juta (kompas, 2007:2). Film horor tidak pernah mati. Film horor digemari, oleh sebab itu film horor tak pernah berhenti diproduksi.

Salah satu hal yang menarik dari film horor yang berkembang di Indonesia adalah tokoh hantunya. Banyak tokoh hantu merupakan perempuan, misalnya saja Kuntilanak, Sundel Bolong, Kalong Wewe, Suster Ngesot, dan sebagainya. Tokoh hantu Sundel Bolong menarik perhatian saya karena berbagai opresi yang melekat dalam dirinya. Ia perempuan, mendapatkan label 'sundel' dari masyarakat akibat profesi yang dilakoninya, ia diperkosa oleh laki-laki, mati karena dibunuh oleh lakilaki, dan difilmkan oleh laki-laki.

Perempuan sebagai Sundel Bolong dalam empat film merupakan objek dari kajian ini. Empat film tersebut yaitu: Pertama, Sundel Bolong (1981) sutradara 
Sisworo Gautama, produksi PT. Rapi Film, dengan pemeran utama Suzzanna. Film ini merupakan film terlaris ketiga di Jakarta pada tahun 1981, dengan pencapaian 301.280 penonton (Kristanto: 2007). Kedua, Malam Jumat Kliwon sutradara Sisworo Gautama (1986), produksi Ram Soraya, dengan pemeran utama Suzzanna. Ketiga, Legenda Sundel Bolong sutradara Hanung Bramantyo (2007), produksi PT. Rapi Film, dengan pemeran utama Jian Batari Anwar. Keempat, Sundel Bolong 2 sutradara Atok (2008) Suharto produksi Libra Interdelta dengan pemeran utama Ayu Azhari.
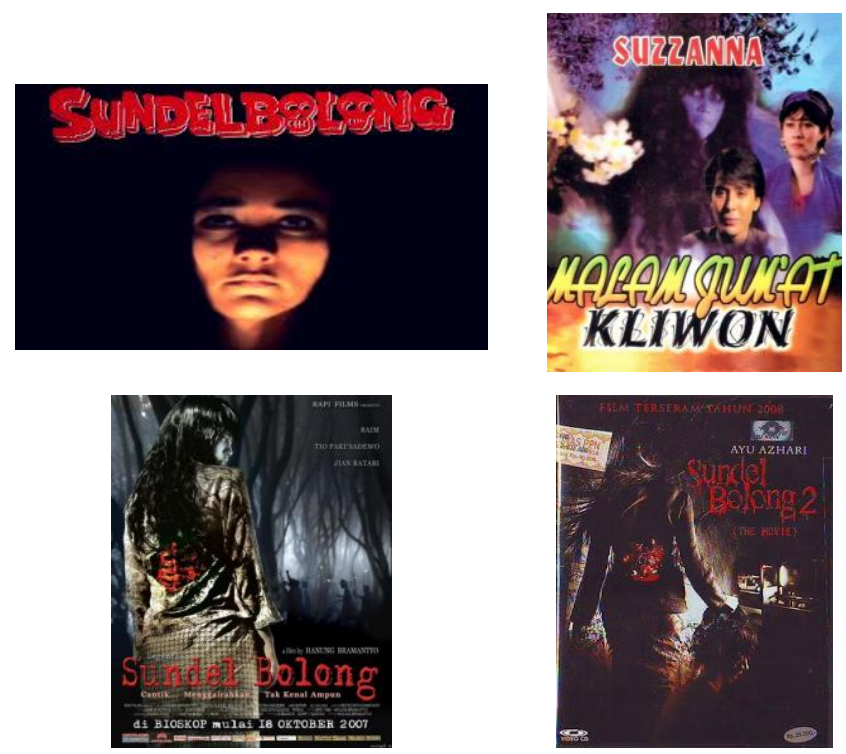

Sumber: Google https://goo.gl/images/q7GSJF

Keempat film tersebut mengisahkan tentang perempuan sebagai hantu Sundel Bolong. Penelitian ini dilakukan dengan menggunakan sudut pandang feminisme, meliputi perempuan, hubungan seksual, femme fatale, dan teori film feminis. Menurut Beauvoir dalam bukunya The Second Sexy (Tong, 2010), perempuan diopresai melalui keliyannannya (otherness). Perempuan adalah Liyan (the Other) karena perempuan bukan laki-laki. Laki-laki adalah bebas, mahluk yang menentukan dirinya sendiri yang mendefinisi makna eksistensinya. Jadi, jika perempuan ingin menjadi diri, seperti laki-laki maka perempuan harus mampu menjadikan dirinya sebagaimana yang diinginkannya. Didasari atau tidak siapapun (perempuan) setiap saat 61 
membangun identitasnya dalam hubungannya dengan sang liyan (others) (Rostiyati, 2017). Perempuan dan the athers mengidentifikasikan diri atau mendefinisikan dirinya, bagaimana berhubungan dan motif apa yang mungkin muncul. Maka ketika interaksi itu terjadi, identitas pun terbentuk. Karenanya, identitas sebetulnya hasil kontruksi dalam berhubungan dengan liyan (Prabasmoro, 2007).

Feminis radikal-libertarian (Smelik: 2011) menekankan bahwa laki-laki sebagai individu, seburuk-buruknya mereka, bukanlah opresor utama perempuan. Musuh utama perempuan adalah sistem patriaki, produk yang dihasilkan oleh keuntungan, prioritas, dan preogratif berabad-abad yang dinikmati laki-laki. Feminis radikal-libertarian mendorong perempuan untuk menghadapi sebagai individu, mengenai sikap dan chauvinis mereka dalam usaha untuk memaksa laki-laki, agar melepaskan diri secara bebas dari keuntungan yang tidak adil, yang telah dianugerahkan oleh patriaki terhadap mereka.

Berkaitan dengan hubungan seksual, Beauviour (2016) menjelaskan bahwa kapasitas reproduksi perempuan telah merampok perempuan dari kemanusiaannya. Sebaliknya kapasitas reproduksi laki-laki tidak mengancam kemanusiaan laki-laki. Setelah hubungan seksual, laki-laki tetap orang yang sama sebelum hubungan seksual. Tetapi jika terjadi fertilisasi setelah hubungan seksual, perempuan berubah dan menjadi bukan orang yang sama ketika hubungan itu terjadi, seorang subjek yang berkesadaran dan individu yang bebas, yang telah berubah menjadi alat untuk melanjutkan kehidupan (Tong, 2010:278). Salah satu cara perempuan membuat keputusan moral adalah aborsi. Ada modus dalam melakukan aborsi. Modus tingkat satu, diri adalah objek satu-satunya dari perhatian perempuan. Modus tingkat dua, kelangsungan hidup adalah hal yang lebih baik. Pandangan mengenai seksualitas lainnya, yaitu menurut Tong (2010:178) yang membahas bahwa pandangan feminis radikal-kultural mengandung pemikiran bahwa hubungan heteroseksual, pada umumnya, dikarakterisasi dengan ideologi objektivasi seksual (laki-laki sebagai 
subjek/tuan; perempuan sebagai objek/budak), yang mendukung kekerasan seksual laki-laki terhadap perempuan.

Perempuan sebagai femme fatale "perempuan mematikan" telah dibuat sebagai proyek pemberontakan demokratis sosial terhadap kesesakan zaman Victoria, di mana perempuan terbatas dalam korset dan didorong ke dalam ideologi sesak dan dunia tertutup menyusut. Kecewa dengan laki-laki dan frustrasi dengan kehidupan yang terbatas, ini sosok femme fatale yang mematikan (Mallick: 2009).

Feminisme adalah sebuah gerakan sosial yang memiliki dampak yang besar terhadap teori film dan kritik. Sinema diambil oleh kaum feminis menjadi sebuah praktik budaya yang mewakili mitos tentang wanita dan kewanitaan, serta tentang laki-laki dan maskulinitas. Isu-isu representasi dan spectatorship sangat penting untuk teori film feminis dan kritik ( Totaro: 2002).

Mitos tentang sundel bolong dijadikan sinema film kaum feminis dan menjadi sebuah praktik budaya tentang perempuan yang mendapat kekerasan seksual laki-laki. Perempuan sebagai femme fatale "perempuan mematikan", karena kecewa dengan laki-laki dan frustrasi dengan kehidupannya. Dengan demikian tujuan penelitian ini adalah untuk mengafirmasi kekerasan seksual yang dialami perempuan dan kebangkitan arwahnya untuk membalas dendam. Arwah dari kematian perempuan yang dilabeli sundel oleh masyarakat dan luka khas (bolong) di punggung inilah yang kemudian sering disebut hantu sundel bolong. Adapun rumusan masalahnya adalah siapa hantu sundel bolong ini dan opresi apa yang melekat dalam dirinya serta kontruksi apa yang dibangun oleh kaum patriarkal.

\section{METODE PENELITIAN}

Untuk pengumpulan data diperoleh dari 4 film yakni Sundel Bolong (1981), Malam Jumat Kliwon (1986), Legenda Sundel Bolong (2007), dan Sundel Bolong 2 (2008). Di samping itu pengumpulan data juga diperoleh dari studi pustaka dan penelurusan di media sosial. Setelah data diperoleh, dilakukan pengkategorian data 
berdasarkan kebutuhan penelitian. Pengkategorian meliputi jalan cerita, motif, dan akhir cerita. Pengkategorian ini akan membantu dalam proses analisis.

Proses analisis dalam penelitian ini terbagi menjadi dua bagian, yakni identifikasi data dan analisis data dengan menggunakan sudut pandang feminisme, meliputi perempuan, hubungan seksual, femme fatale, dan teori film feminis. Analisis data bersifat induktif yakni yakni mengkontruksi makna yang diperoleh dari sumber data atau informasi yang didapat. Dalam kajian ini menggunakan metodologi interpretatif yakni suatu pendekatan tafsiriah. Metode ini digunakan karena penelitian kebudayaan tidak datang dengan sendirinya ataupun dinyatakan langsung oleh realitas budayanya, tetapi direfleksikan, ditafsirkan atau diinterpretasikan, dan direkonstruksi oleh peneliti.Tafsir merupakan lauk utama sajian, sehingga subjektifitas peneliti juga terasa begitu menonjol (Ahimsa, 2006). Menurut Ahimsa dalam menganalisa sebuah film misalnya, bisa menggunakan perspektif antropologi hermeneutik dan interpretatif, yakni menggunakan "teks" sebagai analogi atau model yang memandang, memahami, dan menafsirkan suatu kebudayaan atau gejala sosial budaya tertentu. Dengan model ini seorang peneliti tidak akan memberikan "penjelasan" atau explanation, tetapi akan melakukan "pembacaan" atas gejala sosial budaya tersebut, dan itu berarti peneliti akan memberikan tafsir-tafsir tertentu mengenai gejala tersebut. Tentu saja kadang bersifat subyektifitas, karena setiap penafsiran selalu berada dalam atau berawal dari kerangka berfikir individual tertentu. Dalam konteks seperti itu maka istilah "ilmiah" tidak bisa lagi diberi makna yang sama dengan jika melakukan penelitian di lapangan.

\section{PEMBAHASAN}

\section{Perempuan sebagai Sundel Bolong dalam Film Horor Indonesia}

Pada umumnya karakter perempuan yang menjadi hantu Sundel Bolong merupakan perempuan yang dianggap 'nakal' yang mencoba menjadi seorang istri yang terhormat. Dalam film Sundel Bolong (1981), tokoh Alisa pada mulanya adalah 
seorang pelacur, kemudian menikah dengan tokoh Hendarto dan menjadi istri seorang pelaut. Dalam film Malam Jumat Kliwon (1986), tokoh Minanti merupakan istri kedua dari seorang Raden. Dalam Legenda Sundel Bolong (2007), tokoh Imah merupakan penari ronggeng yang kemudian menikah dengan tokoh Sarpa buruh pemetik teh. Agak berbeda adalah dalam film Sundel Bolong 2 (2008), tokoh Erika yang kemudian menjadi Sundel Bolong bukan perempuan yang sudah menikah, ia merupakan seorang model yang usianya sudah mencapai kepala tiga dan berpacaran dengan laki-laki yang masih duduk di sekolah menengah atas.

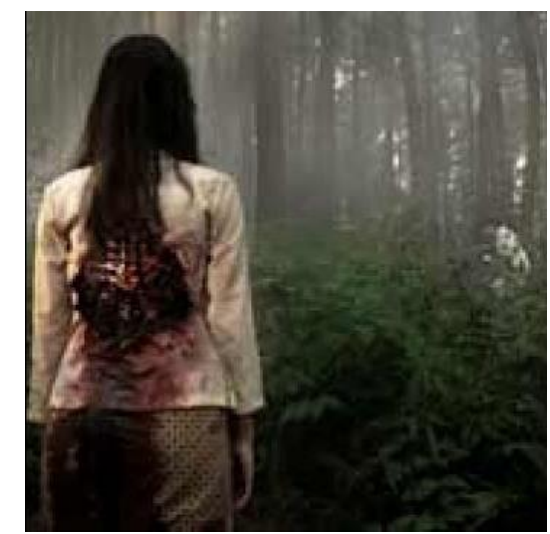

Hantu Sundel Bolong

Pengalaman masa lalu para perempuan yang pada mulanya menjadi pelacur, selingkuhan, penari ronggeng, dan model dengan berlaku seks bebas itulah yang kemudian memunculkan istilah 'sundel' dalam penamaan tokoh hantu. 'Sundel' atau 'sundal' dalam bahasa jawa berarti perempuan nakal, genit, penggoda laki-laki, pelacur. Sementara itu, kata 'bolong' menggambarkan kondisi fisik perempuan dengan punggung yang berlubang. Lubangnya merupakan luka besar berbentuk lingkaran yang menganga. Luka inilah yang menjadi ciri pembeda hantu Sundel Bolong dari hantu-hantu lainnya.

Punggung yang bolong itu adalah luka. Dalam film Sundel Bolong (1981) tidak diceritakan secara gamblang dari mana asal luka tersebut, hanya saja sebelum mati tokoh Alisa bunuh diri dalam kondisi hamil setelah diperkosa secara bergilir. Tokoh Alisa bunuh diri di dalam kamar mandi dan di sana diperlihatkan banyak 65 
darah. Dalam film Malam Jumat Kliwon (1986), luka di punggung itu merupakan tempat lahir bayi. Tokoh Minanti diguna-guna oleh istri tua suaminya sehingga membuat kandungannya menonjol ke belakang tubuh dan bayinya lahir melalui ledakan di punggung. Tokoh Minanti pun meninggal dunia setelah bayinya keluar. Dalam Legenda Sundel Bolong (2007), luka di punggung tersebut berasal dari tertusuknya Imah pada sebuah batu ketika ia dilemparkan ke jurang setelah diperkosa secara bergilir. Berbeda lagi dengan film Sundel Bolong 2 (2008), tokoh Erika yang sedang hamil ditusuk perutnya menggunakan pisau dan punggungnya menggunakan gunting rumput oleh tokoh Ari (yang menghamilinya) dan teman-temannya yang dibayar untuk membunuhnya.

Benang merah dari karakter Sundel Bolong ini adalah: Pertama, perempuan mati dalam kondisi hamil, kehamilannya merupakan hasil hubungan seks bukan dengan pasangan resminya (suami). Kehamilan ini ditengarai akan membuat perempuan malu dan tak tahu harus berkata apa kepada suami dan masyarakat. Hal ini sedikit berbeda dengan apa yang diceritakan dalam film Sundel Bolong 2, tokoh Erika siap hamil, tetapi tokoh Ari sebagai pihak yang menghamilinyalah yang justru tidak siap karena takut karirnya sebagai artis hancur; Kedua, setelah mati perempuanperempuan tersebut menjadi hantu. Mereka melakukan aksi balas dendam kepada laki-laki yang telah memperkosa dan membunuhnya.

\section{Sundel sebagai Objek Hubungan Seksual}

Dalam budaya timur, tokoh Alisa, Minanti, Imah, dan Erika diangap sebagai perempuan 'nakal'. Hal ini disebabkan karena profesi awal mereka sebagai pelacur, selingkuhan, penari ronggeng, dan model berpotensi untuk melakukan hubungan seks di luar pernikahan. Meski semua itu merupakan masa lalu, karena mereka akhirnya menikah (kecuali tokoh Erika) dan berusaha setia pada suaminya, masyarakat tetap melabelinya sebagai perempuan 'nakal'. Label 'sundel' ini yang kemudian menjadi 
afirmasi bagi mereka untuk dianggap layak dijadikan sebagai melayani nafsu lakilaki. Mereka menjadi objek dalam hubungan seksual bahkan yang disertai kekerasan.

Hubungan seksual yang terjadi pada perempuan dan kapasitas reproduksi yang dimilikinya telah 'merampok' perempuan dari kemanusiannya. Tokoh Alisa dan tokoh Imah yang diperkosa secara bergilir ketika suaminya tak ada disampingnya, membuat mereka tampak sebagai objek seksual laki-laki. Perempuan dalam hubungan heteroseksual di film Sundel Bolong dan Legenda Sundel Bolong ini dikarakterisasi dengan ideologi objektivasi seksual. Perempuan menjadi objek atau budak sedangkan laki-laki sebagai subjek atau tuan. Hal ini kemudian mendukung kekerasan seksual laki-laki terhadap perempuan. Perempuan dipaksa dan dengan cara-cara kekerasan seperti dipegangi tangan dan kakinya, tubuhnya dipaksa diciumi, dan pakaiannya dirobek, serta kedua kakinya dilebarkan agar penis laki-laki dapat melakukan penetrasi hingga laki-laki mencapai ‘kepuasan'nya. Hal ini dilakukan berulang kali, usai satu laki-laki, disambung oleh laki-laki lain.

Setelah terjadi hubungan seksual tersebut, fertilisasi pun terjadi. Tokoh Alisa, Minanti, Imah, dan Erika kemudian berubah, bukan lagi menjadi orang yang sama ketika hubungan itu terjadi. Mereka kemudian hamil dan terpaksa menjadi inkubator bagi janin. Dalam hal ini perempuan kemudian berubah dan menjadi alat untuk melanjutkan kehidupan. Perubahan yang terjadi tidak sekadar bagi dirinya, tetapi bagi masyarakat dalam memandang dirinya. Perempuan, hamil, dan sebagai perempuan yang hamil di luar nikah, atau hamil bukan dari benih suaminya. Dalam film Sundel Bolong dan Legenda Sundel Bolong bahkan digambarkan kebimbangan tokoh Alisa dan tokoh Imah karena entah keturunan siapa anaknya, karena ia diperkosa secara bergilir.

"Kesadaran reproduksi" laki-laki berbeda dari "kesadaran reproduksi" perempuan, perbedaan tersebut menurut feminis radikal-kultural O'Brien paling tidak dalam tiga cara. Pertama, tokoh Alisa, Minanti, Imah dan Erika mengalami proses prokreasi sebagai suatu gerakan yang terus-menerus yang terjadi di dalam tubuhnya, 
sementara Rudi, Raden Ngabey Arya Tejo, Danapati, Ari, dan laki-laki lainnya mengalami proses yang sama sebagai gerakan diskontinyu/tidak terus menerus, yang terjadi di luar tubuhnya. Kedua, tokoh Alisa, Minanti, Imah dan Erika harus melakukan kerja reproduksi fundamental yaitu mengandung dan melahirkan, sedangkan yang dapat dilakukan oleh Hendarto, dan Sarpa mencoba membayangkan seperti apa artinya dan bagaimana rasanya hamil dan melahirkan. Ketiga, keterkaitan perempuan dengan anaknya. Perempuan sudah jelas tahu benar tentang anaknya, pada saat kelahiran, anaknya adalah darah dagingnya. Sebaliknya keterkaitan laki-laki dengan anaknya tidak jelas. Laki-laki tidak akan pernah yakin bahwa anaknya secara genetik benar-benar berhubungan dengannya, karena ia tidak akan tahu jika anak itu adalah keturunan dari laki-laki mana pun.

Ketiga poin kesadaran reproduksi ini membuat perempuan semakin tertekan. Ditambah lagi pandangan masyarakat mengenai keistimewaan hubungan antara seorang ibu dan fetus (calon bayi). Misalnya ungkapan-ungkapan tokoh Bi Ijah (asisten rumah tangga tokoh Alisa) mengenai bagaimana fetus tidak memiliki dosa dan oleh karena itu tokoh Alisa harus tetap menjaganya dengan baik. Kepentingan perempuan (Alisa) semakin tersingkirkan akibat adanya tekanan masyarakat mengenai betapa istimewanya hubungan ibu dan fetus. Jika perempuan tidak menjaga kehamilannya, misalnya ketika tokoh Alisa memukul-mukul perutnya karena tidak ingin hamil, maka ia akan dicap sebagai pengandung yang buruk. Begitu pula yang ungkapkan seorang tokoh mantri kepada tokoh Imah ketika tokoh Imah memintanya untuk menggugurkan janin yang sedang dikandungnya. Tokoh Mantri yang seorang laki-laki itu seketika menghina dan menyumpahserapahi tokoh Imah.

\section{Aborsi Alisa: Diri adalah Objek Satu-satunya}

Ke empat tokoh dalam film sundel bolong tersebut, hanya Alisa tokoh perempuan dalam film Sundel Bolong yang melakukan aborsi. Sedangkan tokoh Minanti dalam film Malam Jumat Kliwon meninggal sesaat setelah melahirkan lewat 
punggung. Sementara itu, tokoh Imah dibuang dan mati dengan punggung yang tertancap di batu dan tokoh Erika mati dengan luka di punggungnya akibat ditusuk gunting rumput.

Aborsi merupakan salah satu cara perempuan membuat keputusan moral. Ada modus dalam melakukan aborsi. Modus tingkat satu, diri adalah objek satu-satunya dari perhatian perempuan. Di sini seorang perempuan lebih memilih isolasi daripada keterkaitan. Modus tingkat dua, kelangsungan hidup adalah hal yang lebih baik. Dalam modus ini keperluan didahulukan dari pada keinginan. Perempuan dalam tingkat dua adalah perempuan yang konvensional, penyayang, yang menyamakan kebaikan dengan pengorbanan diri, dan mencoba menomorduakan keinginannya sendiri terhadap keinginan orang lain.

Dalam film Sundel Bolong, tokoh perempuan Alisa akhirnya melakukan aborsi dengan modus tingkat pertama. Baginya, diri adalah objek satu-satunya. Ia tak ingin ada keterkaitan terhadap calon anaknya, dan tak ingin pula ada keterkaitan dengan masyarakat tentang apa yang dilakukannya. Hal ini mengindikasikan bahwa jika peran istri saja sudah membatasi pengembangan diri perempuan, maka peran sebagai ibu lebih membatasi lagi, apalagi menjadi ibu dari anak yang bukan keterunan suaminya. Beauvoir (2016) mengatakan bahwa meskipun mengasuh dan membesarkan anak hingga dewasa dapat mengikat eksistensi seorang perempuan, tetapi ia bersikeras berpendapat bahwa melahirkan bukanlah sebuah tindakan, melainkan semata-mata suatu peristiwa.

\section{Arwah Alisa, Minanti, Imah, dan Erika sebagai Femme Fatale}

Setelah kematiannya, empat tokoh perempuan tersebut menjadi hantu sundel bolong. Wujud fisik mereka diidentikan dengan perempuan berpakaian putih, berambut hitam panjang tak teratur, mata sembab dan cenderung hitam, kadang kala mereka menjadi seorang wanita misterius dan menggoda, yang pesonanya dapat menjerat laki-laki, dan dengan kemampuannya untuk masuk dan menghipnotis 
korbannya. Sebagai femme fatale, sundel bolong mencoba untuk mencapai tujuan tersembunyinya dengan menggunakan tipu muslihat feminin seperti kecantikan, pesona, dan daya tarik seksual. Dalam beberapa situasi, ia menggunakan berbohong atau paksaan daripada pesona. Dia dapat menundukkan musuhnya dengan kekuatan magisnya sebagai senjata. Dia juga dapat menyiratkan dirinya untuk menjadi korban, sehingga membuat musuhnya terjebak dalam situasi di mana ia tidak dapat melarikan diri.

Dalam sundel bolong, arwah tokoh Alisa digambarkan gentayangan dan ingin membalas dendam kepada orang-orang yang telah merusak kehidupannya. Satu persatu tokoh orang suruhan Rudi yang dianggap telah merusak kehidupan tokoh Alisa menemui ajalnya dengan keji dan misterius. Kematian mereka selalu disertai dengan pertemuan dan percumbuan dengan seorang wanita cantik yang mengaku bernama Shinta. Tokoh Rudi dan tokoh mantan "Mami" Alisa pun menemui ajalnya di tangan wanita cantik misterius yang tak lain adalah penjelmaan dari arwah penasaran Alisa. Akhirnya semua orang yang pernah merusak kehidupan tokoh Alisa mati di tangannya dan dendam tokoh Alisa terbalas.

Dalam film Malam Jumat Kliwon, tokoh Pak Ardan digambarkan berniat memerkosa dan membunuh tokoh Ayu, anak dari tokoh Minanti. Namun, nasib tokoh Pak Ardan kemudian digambarkan mati tenggelam di sungai setelah dikejar Sundel Bolong. Demikian pula nasib tokoh Karsiman yang ingin membunuh tokoh Ayu. Tokoh Ayu nyaris dibunuh dengan menggunakan sekop, tetapi sundel bolong melayangkan sekop itu ke dada tokoh Karsiman yang membuatnya mati seketika.

Dalam Legenda Sundel Bolong, tokoh Imah muncul sebagai wanita cantik yang menggoda para laki-laki yang telah memperkosanya dulu. Ia menari di tengah sepi, memperlihatkan liukan tubuhnya yang sintal, dan mengibas-ngibaskan selendangnya sehingga membuat lelaki semakin terpesona dan ingin mendekat. Setelah laki-laki tersebut mendekat kemudian Imah membunuhnya dengan cara menyayat, melukai, dan merusak fisik laki-laki tersebut hingga mati. 
Dalam Sundel Bolong 2, arwah tokoh Erika berusaha menggoda lelaki dengan penampilannya yang seksi. Ia menggunakan pakaian ketat, belahan dada yang terlihat, kaki yang mulus dan jenjang, rambut hitam panjang, senyum manis, mata serta suara yang menggoda untuk mendekati laki-laki yang menjadi targetnya. Lakilaki yang dulu memperkosanya dan membunuh dirinya. Akhirnya semua laki-laki yang memperkosanya mati di tangan tokoh Erika.

Walaupun biasanya besifat jahat, sundel bolong juga muncul sebagai antiheroin dalam cerita sundel bolong bahkan bertobat dan menjadi pahlawan pada akhir kisah, yaitu ketika tokoh laki-laki dan germo mati dibunuhnya, sehingga terungkaplah kasus prostitusi yang kemudian ditangani oleh pihak kepolisian.

Sundel bolong dalam semua film memiliki kekuatan, seksualitas, feminitas, dan kekayaan, tetapi mereka tetap berminat untuk cinta dan berakhir dengan buruk karena mereka menentang konvensi. Dia labeli sebagai seorang "wanita yang buruk;" wanita yang harus mati atau dibuang karena dia bukan wakil dari gambaran idealnya. Sundel bolong yang kecewa bahkan marah terhadap laki-laki dan frustrasi dengan kehidupan yang terbatas (oleh pandangan masyarakat tentang dirinya), kemudian muncul sebagai sosok femme fatale yang mematikan. Dia adalah wanita yang pernah benar-benar merupakan apa yang ingin ia tampakan. Dia tidak bisa diatur, mengancam jiwa laki-laki, dan ia tantangan bagi budaya patriarki. Sundel bolong berwujud femme fatale berkekuatan lebih, dan dengan kemampuan seksual tak terpuaskan, yang mewakili gejala dari kegelisahan laki-laki tentang perempuan. Dia adalah makhluk yang mengancam untuk mengebiri dan memakan korban lakilakinya. Ini merupakan gambaran seorang wanita yang secara seksual berbahaya. Hal ini merupakan ekspresi psikologis ketakutan pria dan kebutuhannya untuk mengendalikan dan menindas mereka.

\section{Subjektivitas Perempuan dalam Narasi}


Subjektivitas perempuan dapat dieksplorasi dalam kaitannya dengan struktur narasi film. Narasi adalah salah satu cara subjektivitas mereproduksi; setiap cerita berasal dari keinginan struktur subyek dan dari catatan dalam kode sosial dan budaya. Struktur narasi didefinisikan oleh keinginan oedipal, dipahami secara ekonomi sosialpolitik yang didominasi oleh kontrol laki-laki terhadap perempuan dan sebagai cara menekankan seksual subjektivitas. Hasrat seksual terikat dengan keinginan terhadap pencarian kebenaran. Mencari kebenaran adalah keunggulan dan keinginan laki-laki, sedangkan subjek perempuan adalah sesuatu yang dianggap misteri susah dimengerti keinginannya.

Narasi tidak oedipal terdapat dalam isi dan struktur, dengan mendistribusikan pada peran dan perbedaan serta kekuasaan dan posisi. Salah satu fungsi narasi adalah untuk 'menggoda' perempuan ke femininitas dengan atau tanpa persetujuan mereka. Subjek perempuan dibuat untuk keinginan feminitas. Keinginan dalam narasi yang terikat erat dengan kekerasan terhadap perempuan dan teknik narasi sinematik yang mencerminkan dan mempertahankan bentuk-bentuk penindasan perempuan.

Demikianlah, salah satu tokoh hantu perempuan di Indonesia adalah sundel bolong. Ciri pembeda utama sundel bolong dan hantu lainnya adalah punggungnya yang terdapat luka berbentuk lingkaran yang tampak seperti lubang alias bolong. Sundel bolong merupakan hantu jelmaan dari perempuan yang mati dalam keadaan hamil dan adanya luka di punggung. Pada tahun 1980an, lubang di punggung perempuan yang kemudian menjadi hantu sundel bolong merupakan bekas luka melahirkan. Minanti diguna-guna sehingga kandungannya beralih dari perut ke punggung dan melahirkan dengan cara punggungnya meledak. Namun, pada tahun 2000an, lubang di punggung merupakan hasil dari kekerasan yang terjadi saat pembunuhan berlangsung. Tubuhnya dibuang ke jurang dan tertancap batu sehingga menimbulkan luka di punggung. Selain itu, ada juga penusukkan punggung yang menggunakan gunting rumput, karena menggunakan pisau tidak juga segera mati. 


\section{Pandangan sundel mengafirmasi kekerasan seksual Perempuan}

Perempuan-perempuan yang mati dengan luka di punggung dan kemudian menjadi hantu ini pada awalnya merupakan perempuan 'sundel' alias perempuan nakal. Meski mereka telah bertaubat dan ingin menjadi perempuan yang setia pada pasangannya (suaminya, kecuali dalam Sundel Bolong 2) masyarakat tetap memandangnya sebagai sundel. Pandangan sundel ini kemudian mengafirmasi kekerasan seksual yang harus dialami perempuan-perempuan ini meski telah menikah (dalam Sundel Bolong dan Legenda Sundel Bolong). Arwah dari kematian perempuan yang dilabeli sundel oleh masyarakat dan luka (lubang) khas (bolong) di punggung inilah yang kemudian sering disebut hantu sundel bolong.

Dari empat motif kematian perempuan dalam film bertema sundel bolong salah satunya adalah aborsi, tiga lainnya dibunuh. Tokoh Alisa dalam sundel bolong berbeda dengan tokoh perempuan dalam film lainnya yang juga kemudian menjadi hantu sundel bolong. Tokoh Alisa berani membuat keputusan moral yang menjadikan dirinya adalah objek satu-satunya. Ia melakukan aborsi, dan memilih untuk (risiko) mati di tangan sendiri daripada dibunuh oleh musuhnya.

Kematian seluruh tokoh perempuan merupakan kebangkitan tokoh-tokoh tersebut dalam wujud lain. Tokoh Alisa, Minanti, Imah, dan Erika kemudian hadir sebagai hantu. Selain berwujud hantu yang menakutkan, mereka menjadi seorang wanita penuh pesona, menggoda, sekaligus misterius. Sebagai femme fatale, sundel bolong mencoba untuk mencapai tujuan tersembunyinya dengan menggunakan tipu muslihat feminin seperti kecantikan, pesona, dan daya tarik seksual. Dia dapat menundukkan lawannya dengan kekuatan magisnya. Dia juga dapat menyiratkan dirinya sebagai korban, sehingga terjebak dalam situasi dimana laki-laki tidak dapat melarikan diri.

Penindasan seksualitas perempuan adalah subteks penting dari film horor bertema sundel bolong. Subjektivitas perempuan dapat dieksplorasi melalui struktur narasi film. Struktur narasi didefinisikan oleh keinginan oedipal, yang didominasi 
oleh kontrol laki-laki terhadap perempuan. Salah satu fungsi narasi adalah untuk 'menggoda' perempuan ke femininitas dengan atau tanpa persetujuan mereka. Keinginan dalam narasi yang terikat erat dengan kekerasan terhadap perempuan dan teknik narasi sinematik mencerminkan dan mempertahankan bentuk penindasan perempuan.

\section{PENUTUP}

Perempuan selalu menjadi objek seksual dalam sebuah film, bahkan perempuan selalu menjadi "ikon" di media massa, karena tubuh perempuan dianggap sebagai "barang seni, sesuatu yang indah". Perempuan ditampilkan dan dieksploitasi secara bebas, karena keindahan dan kecantikannya digambarkan sebagai karakter yang menarik. Visualitas ini bukan sekadar objek, tetapi sesuatu yang menyimpan berbagai gagasan dan nilai yang telah dikontruksikan oleh kekuatan sosial. Demikian pula yang terdapat dalam empat film tentang sundel bolong tersebut menggambarkan perempuan sebagai korban penindasan kaum laki-laki.

Keindahan tubuh perempuan rusak bukan saja disebabkan oleh kesalahpahaman dalam budaya atau penyakit. Laki-laki sesungguhnya punya peranan dalam memberikan penilaian terhadap tubuh perempuan. Banyak kasus laki-laki justru menjadi penyebab kekerasan terhadap perempuan yang sangat mengerikan. Tubuh sama sekali tidak dihargai, termasuk jiwa perempuan. Sering kali kekerasan yang dilakukan laki-laki terhadap perempuan berkaitan erat dengan unsur seksualitas. Seksualitas perempuan hanya dilihat sebagai "fenomena natural" yang universal tidak dapat diubah. Padahal seksualitas terkait dengan kontruksi sosial dan perasaan seksual manusia untuk menunjukkan identitas kelaminnya.

Seorang ahli psikologis Freud seperti yang diungkapkan oleh Sutrisno (2005) mengatakan bahwa anatomi adalah takdir, artinya perempuan ditakdirkan tidak akan pernah meraih harapan, keinginan, dan hasrat dalam hidupnya. Ia menempatkan seksualitas perempuan pada posisi pasif, sedangkan laki-laki aktif. Secara sadar atau 
tidak, langsung atau tidak, psikologis ini mempengaruhi laki-laki untuk menempatkan perempuan pada posisi lebih rendah, maka selanjutnya laki-laki memiliki kuasa atas perempuan dan bisa melegitimasi tindak kekerasan terhadap perempuan. Keadaan dan persoalan kaum perempuan dalam masyarakat juga lahir dari latar belakang budaya dan sejarah uang yang membuat suatu kelas menguasai kelas lain dan lakilaki menguasai perempuan. Mereka adalah produk kelas dan seks, laki-laki dianggap pekerja yang memiliki uang sedangkan perempuan di sektor domestik yang tergantung secara ekonomi. Pandangan ini memberi kontribusi pada ideologi patriarkal, di mana nilai-nilai patriarkal selalu melingkupi kehidupan perempuan.

Kekerasan seksual terhadap perempuan, seperti halnya yang terjadi pada 4 tokoh perempuan dalam film sundel bolong, merupakan masalah budaya machoisme, di mana kekuasaan laki-laki sangat jelas. Kekerasan yang muncul akibat ketakutan laki-laki menghadapi resiko bermula dari hubungan seksual di luar pernikahan, tanpa cinta, dan menyebabkan kehamilan. Kejadian ini memunculkan tindakan seperti pembunuhan pada perempuan oleh si laki-laki, aborsi terhadap terhadap kandungan si perempuan, tekanan psikologis dan sanksi masyarakat terhadap perempuan.

Hal inilah yang dialami perempuan sundel bolong, merupakan objek dalam hubungan seksual dan kematian perempuan sundel merupakan kebangkitannya dalam wujud hantu dan muncul sebagai sosok femme fatale. Penindasan seksualitas perempuan adalah subteks penting dari film horor bertema Sundel Bolong. Pandangan sundel ini mengafirmasi kekerasan seksual yang harus dialami perempuan-perempuan ini.

\section{DAFTAR PUSTAKA}

Atok Suharto. 2008. Sundel Bolong 2. Libra Interdelta

Ahimsa, Shri Heddy. 2006. Esei-Esei Antropologi. Teori, Metodologi dan Etnografi. Yogyakarta: Kepel Press

Bramantyo, Hanung. 2007. Legenda Sundel Bolong. PT Rapi Film

Beauvior, Simone. 2016. Second Sex, Fakta dan Mitos. Yogyakarta: Pustaka Narasi 
Creed, Barbara. 1993. The Monstrous-Feminine: Film, Feminism, Psychoanalysis. London : Routledge

Gautama, Sisworo. 1986. Malam Jumat Kliwon. Jakarta : PT Ram Soraya

Kristanto, JB. 2007. Katalog Film Indonesia 1926-2007. Jakarta: Nala

Mallick, Nazia. 2009. The Femme Fatale in Cinema. Tersedia di http://blogcritics.org/video/article/the-femme-fatale-in-cinema/ [4 Juni 2011]

Prabasmoro, Aquarini Priyatna. 2007. Seks dan Seksualitas Perempuan Dalam Kebudayaan Kontemporer. Dalam Kajian Budaya Feminis. Yogyakarta: Jalasutra

Rostiyati, Ani. 2017. "Perempuan Punk, Budaya Perlawanan Terhadap Gender Normatif (Kasus di Desa Cijambe Ujungberung)" dalam Jurnal Patanjala Vol. 9.2 Juni 2017. Hal. 261-265.

Sutrisno, Mudji. 2005. Teori-teori Kebudayaan. Ygyakarta: Kanisius

Smelik, Anneke. Feminist Film Theory. Tersedia di http://www.let.uu.nl/womens_studies/anneke/filmtheory.html [4 Juni 2011]

Tong, Rosemarie Putnam, 2010. Feminist Thought. Yogyakarta: Jalasutra

Totaro, Donato. 2002. The Final Girl: A Few Thoughts on Feminism and Horror. http://www.horschamp.qc.ca/new_offscreen/final_girl.html [4 Juni 2011] 